\title{
Psychometric Analysis Regarding the Barriers to Providing Effective Insulin Treatment in Type 2 Diabetic Patients
}

\author{
Eu Jeong $\mathrm{Ku}(1) \cdot$ Dong-Hwa Lee $\cdot$ Hyun Jeong Jeon · Frank Park • \\ Tae Keun Oh
}

Received: September 3, 2020 / Accepted: October 10, 2020 / Published online: October 24, 2020

(C) The Author(s) 2020

\section{ABSTRACT}

Introduction: A psychometric analysis on type 2 diabetic (T2D) patients was performed to assess whether glycated hemoglobin (HbA1c) levels were dependent upon either the psychologic or economic attitude toward the use of insulin as a treatment for their diabetic condition.

Methods: A cross-sectional study was designed using 271 patients with T2D who regularly visited a tertiary referral hospital in South Korea from June 2019 to December 2019. Each patient enrolled in this protocol was treated with insulin for at least 6 months, had recordings of their plasma HbA1c measurement, and completed validated questionnaires consisting of items focusing on patient attitudes toward insulin use [Insulin Treatment Appraisal Scale (ITAS)] and

E. J. Ku · D.-H. Lee · H. J. Jeon · T. K. Oh $(\bowtie)$ Department of Internal Medicine, Chungbuk National University Hospital, Cheongju-si, Republic of Korea

e-mail: tgohkjs@chungbuk.ac.kr

E. J. Ku · D.-H. Lee · H. J. Jeon · T. K. Oh Department of Internal Medicine, Chungbuk National University College of Medicine, Cheongjusi, Republic of Korea

F. Park

Department of Pharmaceutical Sciences, University of Tennessee Health Science Center College of Pharmacy, Memphis, TN, USA cost-related issues related to diabetic supply purchase. Multiple regression analyses were performed to determine the association between their HbA1c and each item on the questionnaires.

Results: In both males and females, there was a significant association $(P<0.05)$ between HbA1c levels and multiple items on the ITAS questionnaire, which are generally regarded as a negative perception (ITAS 1 "personal failure" and ITAS 2 "illness severity" in males and ITAS 12 "expected harm" and ITAS 15 "restrictiveness" in females). In females, however, not all perceptions were negative, since one item (ITAS 8 "anticipated effect") was correlated with the measurement of a lower HbA1c level ($0.495 \pm 0.211, P<0.05)$. There was no association between the levels of HbA1c and the cost of insulin or associated diabetic supplies. Since only a few patients in this study chose to reduce their drug dosing because of cost, the resistance to using insulin is likely not driven by economic reasons.

Conclusion: The psychometric results of the ITAS suggested that HbA1c levels were directly associated with a positive attitude of the patient to willingly use insulin for therapy. The cost of the insulin therapy was not associated with HbA1c levels. These findings in the Korean population suggest that continued education is needed to ensure that T2D patients have a reinforced positive psychology toward the use of insulin in the control of their glycemia. 
Keywords: Cost; HbA1c; Psychometric analysis; Psychologic insulin resistance; Type 2 diabetes mellitus

\section{Key Summary Points}

Why carry out this study?

Although the efficacy of insulin is well established, there are still barriers especially related to psychometry and economic status of patients with T2DM.

The effect of 'psychologic insulin resistance (PIR),' a complex concept involving psychologic factors related to reluctance to initiate and adhere to insulin, on patients receiving insulin in the long-term is uncertain.

This study aimed to explore whether glycemic control was associated with either psychologic resistance to the use of insulin as a treatment for diabetes or related to the cost of purchasing diabetic supplies.

\section{What was learned from the study?}

Negative perceptions about insulin treatment were significantly associated with higher HbA1c in both genders. On the positive side, females showed lower HbA1c. In this study, an estimated $40 \%$ of patients showed a negative view in terms of price of diabetic supplies, but insulin therapy was rarely restricted because of price.

The results of this study suggest that continued education is needed to ensure that T2D patients have a reinforced positive psychology toward the use of insulin in the control of their glycemia.

\section{DIGITAL FEATURES}

This article is published with digital features to facilitate understanding of the article. You can access the digital features on the article's associated Figshare page. To view digital features for this article go to https://doi.org/10.6084/m9. figshare.13067198.

\section{INTRODUCTION}

Type 2 diabetes (T2D) is characterized by chronic hyperglycemia due to a gradual decrease in insulin secretion and insulin resistance in multiple target organs, including the skeletal muscle, liver, and adipose tissue $[1,2]$. An effective therapy to treat T2D and delay or prevent any diabetes-related complications is through the administration of insulin [3-5].

Despite the established efficacy of insulin, patients are not always willing to initiate and maintain strict adherence to the use of this treatment regimen [6-8]. The reluctance to initiate and adhere to insulin treatment by the patient and, in some cases, the prescribers may be attributed to an emerging phenomenon known as 'psychologic insulin resistance' (PIR) [9-11]. Some of the psychologic factors associated with PIR that can weigh on the patient can involve, among others, their fear of pain from the self-administration process, concerns about adverse physical health effects (e.g., body weight gain and inadvertent hypoglycemia), erroneous health beliefs (e.g., insulin causes chronic diabetic complications), doubts about the need for or even effectiveness of insulin, frustrations over continued diabetes progression, feelings of individual failure, and concerns regarding its impact on social relationships $[12,13]$. Moreover, patients may be personally influenced by prior experiences of their own or close friends using insulin or other injectable drugs or have their own misconceived perception about their current diabetic state. For these reasons, PIR may play an important role in the decision by the patient to use insulin for the treatment of their hyperglycemia. Alternatively, less understood factors that may confound the use of insulin by 
hyperglycemic patients to control their glycemia could be associated with the socioeconomics of the patient population, which could include the perceived high cost of insulin and other diabetic supplies [14, 15].

For these reasons, the current study was designed to enroll a Korean population of T2D patients to better understand the positive or negative appraisal of insulin use by using a validated questionnaire to correlate their psychometry with HbA1c levels, which will provide an index of glycemic control.

\section{METHODS}

\section{Study Design and Participants}

Patients who regularly visited the Diabetes Center in Chungbuk National University Hospital, which is a tertiary referral hospital in Chungcheongbuk-do Province in South Korea, between June 2019 and December 2019 were enrolled into this study. The participants were recruited into this study if they were T2D patients ( $\geq 18$ years of age) who had continuously received insulin therapy for at least the prior 6 months. Two hundred seventy-nine participants met these initial criteria, but eight were removed because of the exclusion criteria, so this provided a net total of 271 eligible patients for this study. The exclusion criteria for this study were: (1) not having type 2 diabetes (i.e., type 1 diabetes, gestational diabetes, or diabetes caused by secondary factors), (2) actively using anticancer treatment, (3) taking medications that could affect glucose metabolism, such as corticosteroids, immunomodulating agents, or appetite suppressants, (4) inability to comprehend the questionnaire because of cognitive impairment, dementia, or antipsychotics, and (5) lack of any measurement for glycated hemoglobin within the preceding 3 months prior to survey enrollment. Reasons for exclusion from our study were either dementia ( 2 patients) or a lack of measurements for HbA1c levels (6 patients). The sample size for this study was calculated using $\mathrm{G}^{\star}$ Power (version 3.1) with a type I error at 0.05 , powered at 0.95 , a medium effect size at 0.15 , and an estimated 70\% prevalence of PIR among patients with diabetes as in similar study [16]. The minimum required sample size was calculated as 172 patients at the included predictors, which was far lower than the eligible number of patients that we recruited (271 patients). The study was performed according to the principles of the revised Declaration of Helsinki, a statement of ethical principles to provide guidance to physicians and other participants in medical research involving human subjects, and approved by the ethics committee of Chungbuk National University Hospital (IRB no. 2019-05019). Informed consent was obtained from all participants prior to inclusion in the study.

\section{Clinical and Anthropometric Measurement}

Sociodemographic information from each patient was obtained, such as gender, age, marital status, level of education, household income, and caregiving status. Marital status was categorized as single, married, divorced, or widowed. The education level was classified as uneducated, elementary school graduate, middle school graduate, high school graduate, or university graduate and beyond. Economic status was categorized by household annual income: (I) < 8200 USD; (II) 8200-41,030 USD; (III) 41,030-82,060 USD; (IV) $\geq 82,060$ USD.

From the electronic medical records, the following specific information regarding diabetes was obtained: (1) duration of diabetes; (2) familial history of diabetes; (3) duration of insulin use; (4) types of insulin regimen; (5) daily insulin dosage; (6) concomitant medications such as antihypertensive drugs, statins, and antiplatelet agents; (7) current state of any comorbidities; (8) chronic diabetic complications.

Height and body weight were measured using standard methods. Body mass index (BMI) was calculated by dividing the body weight by the square of the height $\left(\mathrm{kg} / \mathrm{m}^{2}\right)$. Systolic and diastolic blood pressure was measured by trained nurses using a sphygmomanometer in patients after they had sat and rested for at least $15 \mathrm{~min}$.

Venous sampling to measure HbA1c was performed on the day of the questionnaire 
survey. HbA1c was measured by affinity chromatography (Bio-Rad Laboratories, Hercules, CA, USA) in a National Glycated Hemoglobin Standardization Program level II-certified laboratory.

\section{Questionnaire}

The validated and structured questionnaires [insulin treatment appraisal scale (ITAS)] were conducted by a trained professional diabetes education nurse. The ITAS included 16 negative and 4 positive questions (ITAS $3,8,17,19$ ) that reflected the attitudes and perceptions about insulin treatment [17]. Each question of the ITAS is ranked using a 5-point Likert scale indicating how strongly participants agree or disagree with each of the items: $1=$ strongly disagree, $2=$ disagree, $3=$ neither agree nor disagree, $4=$ agree, or $5=$ strongly agree. The positively worded items were reversed for their scoring. The total ITAS score is the summation of the reversed positive (4-20) and negative ITAS (16-80) scores, resulting in a total score between 20 and 100. A higher score reflects a higher PIR [17].

In addition to the ITAS, we designed a new series of questions about any cost-related concerns and general attitudes about insulin treatment and diabetic self-care. All of the questions started with "Did you..." (1) ever use less insulin doses than prescribed because of high cost?, (2) think insulin and diabetes supplies including insulin syringes or pen needles, lancets, blood glucose test strips, and alcohol swabs were expensive?, (3) have regular meals?, (4) eat breakfast all the time?, (5) measure blood glucose levels every morning three or more times a week?, (6) adjust the insulin dose according to the blood glucose level?, (7) lose consciousness because of serious hypoglycemia?, and (8) take smaller doses of insulin than prescribed because of concerns about hypoglycemia?

\section{Statistical Analysis}

All statistical analyses were performed using SPSS version 24.0 (IBM Co. Chicago, IL, USA). Data were analyzed using descriptive statistics.
Continuous variables were described by means and standard deviations. Categorical variables were described by numbers and percentages. Due to potential differences in the psychologic factors between male and female participants, the analyses were performed by separating each sex. Missing data were not imputed by other variables. Simple linear regression analyses were used to explore the unadjusted associations between HbA1c with either the individual negative or positive or the total ITAS scores. In the fully adjusted model, age, marital/economic/ educational status, familial history of diabetes, duration of diabetes, type of insulin injection, daily insulin dose/bodyweight, comorbidities, and caregiving status were considered in the analyses. Regression coefficients with standard errors and 95\% confidence intervals (95\% CI) are reported as $\beta \pm \mathrm{SE}(95 \% \mathrm{CI}) . \beta$ indicates the differences in the mean HbA1c (\%) for each independent variable. All statistical tests were two-sided, and significant differences were accepted if $P<0.05$.

\section{RESULTS}

\section{Demographic and Clinical Characteristics of Study Participants}

General information about the demographic and clinical characteristics of the study participants are shown in Table 1 . In brief, the mean age of the participants was $59.9 \pm 12.3$ years; they were overweight (BMI $26.7 \pm 4.1 \mathrm{~kg} / \mathrm{m}^{2}$ ), with a slightly higher number of males (144; $53.1 \%)$ than females $(127 ; 46.9 \%)$. Females were significantly older $(P=0.024)$ than the males by an average of 3.3 years. In terms of diabetes-related characteristics, females had a significantly higher level of HbA1c than males $(P=0.010)$. The mean duration of diabetes was $16.1 \pm 9.3$ years while the time frame since the initiation of insulin therapy was $4.8 \pm 4.9$ years. In the ITAS questionnaire, the sum of positive $(15.0 \pm 2.2$ vs. $15.0 \pm 1.9)$ and negative $(45.3 \pm 8.7$ vs. $45.8 \pm 9.0)$ scores was not significantly different between the male and female participants, respectively. However, the following sections describes that both males 
Table 1 Demographic and clinical characteristics of study participants $(n=271)$

\begin{tabular}{|c|c|c|c|}
\hline Variables & Total $(n=271)$ & Male $(n=144)$ & Female $(n=127)$ \\
\hline Age, years & $59.9 \pm 12.3$ & $58.4 \pm 12.5$ & $61.7 \pm 11.9$ \\
\hline SBP, mmHg & $128 \pm 15.7$ & $128.0 \pm 16.2$ & $128.0 \pm 15.2$ \\
\hline DBP, mmHg & $69.4 \pm 11.3$ & $71.5 \pm 10.6$ & $67.0 \pm 11.7$ \\
\hline BMI, $\mathrm{kg} / \mathrm{m}^{2}$ & $26.7 \pm 4.1$ & $26.1 \pm 3.8$ & $27.4 \pm 4.3$ \\
\hline Duration of diabetes, years & $16.1 \pm 9.3$ & $15.1 \pm 9.4$ & $17.2 \pm 9.4$ \\
\hline Familial history of diabetes & $163(60.1)$ & $86(60.1)$ & $77(61.1)$ \\
\hline \multicolumn{4}{|l|}{ Marital status } \\
\hline Single & $28(10.3)$ & $19(13.2)$ & $9(7.1)$ \\
\hline Married & $199(73.4)$ & $113(78.5)$ & $86(67.7)$ \\
\hline Divorced/widowed & $44(16.3)$ & $12(8.4)$ & $32(25.2)$ \\
\hline \multicolumn{4}{|l|}{ Education } \\
\hline None & $8(3.0)$ & 0 & $8(6.3)$ \\
\hline Elementary school & $43(15.9)$ & $12(8.3)$ & $31(24.4)$ \\
\hline Middle school & $59(21.8)$ & $29(20.1)$ & $30(23.6)$ \\
\hline High school & $100(36.9)$ & $57(39.6)$ & $43(33.9)$ \\
\hline$\geq$ University & $61(22.5)$ & $46(31.9)$ & $15(11.8)$ \\
\hline \multicolumn{4}{|l|}{ Economic status ${ }^{\mathrm{a}}$} \\
\hline I (low) & $122(45.0)$ & $56(38.9)$ & $66(52.0)$ \\
\hline II & $99(36.5)$ & $55(38.2)$ & $44(34.6)$ \\
\hline III & $37(13.7)$ & $25(17.4)$ & $12(9.4)$ \\
\hline IV (high) & $10(3.7)$ & $7(4.9)$ & $3(2.4)$ \\
\hline No response & $3(1.1)$ & $1(0.7)$ & $2(1.6)$ \\
\hline \multicolumn{4}{|l|}{ Caregiving status } \\
\hline None & $104(38.4)$ & $50(34.7)$ & $54(42.5)$ \\
\hline Family caregivers & $164(60.5)$ & $93(64.6)$ & $71(55.9)$ \\
\hline Paid caregivers & $3(1.1)$ & $1(0.7)$ & $2(1.6)$ \\
\hline Duration since starting insulin therapy, years & $4.8 \pm 4.9$ & $4.4 \pm 4.6$ & $5.2 \pm 5.1$ \\
\hline \multicolumn{4}{|l|}{ Type of insulin regimen } \\
\hline Basal insulin & $114(42.1)$ & $67(46.5)$ & $47(37.0)$ \\
\hline Basal-bolus insulin & $47(17.3)$ & $24(16.7)$ & $23(18.1)$ \\
\hline Premixed insulin & $110(40.6)$ & $53(36.8)$ & $57(44.9)$ \\
\hline Total daily insulin dose, units $/ \mathrm{kg} /$ day & $0.62 \pm 0.55$ & $0.52 \pm 0.33$ & $0.75 \pm 0.69$ \\
\hline Compliance for insulin therapy & $0.91 \pm 0.14$ & $0.92 \pm 0.14$ & $0.90 \pm 0.14$ \\
\hline
\end{tabular}


Table 1 continued

\begin{tabular}{|c|c|c|c|}
\hline Variables & Total $(n=271)$ & Male $(n=144)$ & Female $(n=127)$ \\
\hline \multicolumn{4}{|l|}{ Concomitant medication } \\
\hline ACE inhibitor or ARB & $150(55.4)$ & $78(54.2)$ & $72(56.7)$ \\
\hline$\beta$-Blockers & $59(21.8)$ & $31(21.5)$ & $28(22.0)$ \\
\hline Calcium channel blockers & $113(41.7)$ & $55(38.2)$ & $58(45.7)$ \\
\hline Diuretics & $67(24.7)$ & $36(25.0)$ & $31(24.4)$ \\
\hline Statin & $190(70.1)$ & $95(66.0)$ & $95(74.8)$ \\
\hline Antiplatelet agent & $112(41.3)$ & $64(44.4)$ & $48(37.8)$ \\
\hline \multicolumn{4}{|l|}{ Comorbidities } \\
\hline Hypertension & $155(57.2)$ & $77(53.5)$ & $78(61.4)$ \\
\hline $\mathrm{CHD}$ & $65(24.0)$ & $41(28.5)$ & $24(18.9)$ \\
\hline CVA & $30(11.1)$ & $19(13.2)$ & $11(8.7)$ \\
\hline PAD & $17(6.3)$ & $12(8.3)$ & $5(3.9)$ \\
\hline Retinopathy & $129(47.6)$ & $64(45.1)$ & $65(51.2)$ \\
\hline Nephropathy ${ }^{\mathrm{b}}$ & $74(27.3)$ & $42(29.2)$ & $32(25.2)$ \\
\hline Neuropathy & $112(41.3)$ & $59(41.0)$ & $53(41.7)$ \\
\hline \multicolumn{4}{|l|}{ Psychologic distress } \\
\hline ITAS positive score & $15.0 \pm 2.1$ & $15.0 \pm 2.2$ & $15.0 \pm 1.9$ \\
\hline ITAS negative score & $45.5 \pm 8.8$ & $45.3 \pm 8.7$ & $45.8 \pm 9.0$ \\
\hline HbA1c, \% & $8.4 \pm 1.6$ & $8.2 \pm 1.5$ & $8.7 \pm 1.7$ \\
\hline $\mathrm{HbAlc}, \mathrm{mmol} / \mathrm{mol}$ & $68.4 \pm 17.4$ & $65.9 \pm 16.2$ & $71.3 \pm 18.4$ \\
\hline
\end{tabular}

Data are expressed as a percentage (mean \pm standard deviation)

$A C E i$ angiotensin receptor blocker, $A R B$ angiotensin receptor blocker, $B M I$ body mass index, $C H D$ coronary heart disease, CVA cerebrovascular accident, $D B P$ diastolic blood pressure, HbAlc glycated hemoglobin, ITAS Insulin Treatment Appraisal Scale, $P A D$ peripheral arterial disease, $S B P$ systolic blood pressure

${ }^{a}$ Household income category: I, 8200 USD per year; II, 8200-41,030 USD per year; III, 41,030-82,060 USD per year; IV, $>$ 82,060 USD per year

${ }^{\mathrm{b}} \geq$ Stage 3 chronic kidney disease (estimated glomerular filtration rate $\leq 60 \mathrm{ml} / \mathrm{min} / 1.73 \mathrm{~m}^{2}$ )

and females exhibited significant associations between specific items in the questionnaire with the levels of measured HbA1c.

\section{Association Between ITAS Score and Hba1c in Male Patients}

Table 2 shows the results of a multiple linear regression analysis comparing the various ITAS items with $\mathrm{Hb} 1 \mathrm{Ac}$ levels in the male patients. In the unadjusted model, several ITAS items were significantly associated $(P<0.05)$ with increased HbA1c $\left(\beta \pm \mathrm{SE}\left[\begin{array}{lll}95 \% & \mathrm{CI}\end{array}\right)\right.$. More specifically, the HbA1c levels in males were associated with several negative perceptions in the use of insulin, including their disease progression (ITAS 2, 'taking insulin means my diabetes has become much worse') $[0.250 \pm 0.124$ 
Table 2 Multiple linear regression models comparing the psychologic status in males with HbAlc

\begin{tabular}{|c|c|c|c|c|c|c|c|}
\hline \multicolumn{4}{|l|}{ Crude model } & \multicolumn{4}{|c|}{ Fully adjusted model } \\
\hline$\overline{\Delta \mathrm{HbA1c}(\%)}$ & $\beta \pm S E$ & 95\% CI & $P$ value & $\overline{\Delta \mathrm{HbA1c}(\%)}$ & $\beta \pm \mathrm{SE}$ & $95 \% \mathrm{CI}$ & $P$ value \\
\hline ITAS 2 & $0.250 \pm 0.124$ & $0.005-0.495$ & 0.045 & ITAS 1 & $0.242 \pm 0.120$ & $0.004-0.480$ & 0.046 \\
\hline ITAS 9 & $0.236 \pm 0.116$ & $0.006-0.465$ & 0.044 & ITAS 2 & $0.306 \pm 0.134$ & $0.040-0.572$ & 0.025 \\
\hline ITAS 20 & $0.346 \pm 0.125$ & $0.099-0.594$ & 0.006 & & & & \\
\hline
\end{tabular}

The analysis was calculated with adjustment for the following factors: (1) age, (2) marital/economic/educational status, (3) familial history of diabetes, (4) duration of diabetes, (5) type of insulin injection, (6) daily insulin dose/bodyweight, (7) comorbidities, and (8) caregiving status

CI confidential interval, ITAS Insulin Treatment Appraisal Scale, ITAS I taking insulin means I have failed to manage my diabetes with diet and tablets, ITAS 2 taking insulin means my diabetes has become much worse, ITAS 9 insulin causes weight gain, ITAS 20 taking insulin makes me more dependent on my doctor, $S E$ standard errors

Values were significance at $P<0.05$

(0.005-0.495)], concerns about their potential weight gain (ITAS 9, 'insulin causes weight gain,' $0.236 \pm 0.116[0.006-0.465]$ ), and their perceived reliance on their physician (ITAS 20, 'taking insulin makes me more dependent on my doctor,' $0.346 \pm 0.125$ [0.099-0.594]).

After adjusting for confounding factors, such as age, marital/economic/educational status, familial history of diabetes, duration of diabetes, type of insulin injection, daily insulin dose/body weight, comorbidities, and caregiving status, there was still a significant correlation between increased levels of HbA1c with the negative attitudes about insulin treatment. In particular, the male participants remained concerned about their disease progression (ITAS 2, "taking insulin means my diabetes has become much worse"), but they also felt negatively about themselves because of their inability to control their blood glucose using other methods (ITAS 1 "taking insulin means I have failed to manage my diabetes with diet and tablets") $(0.306 \pm 0.134 \quad[0.040-0.572] \quad$ and $0.242 \pm 0.120$ [0.004-0.480], respectively, all $P<0.05)$.

\section{Association Between ITAS Score and Hba1c in Female Patients}

Table 3 presents the results of the multiple linear regression analysis for the effects of the psychologic status on glycemic control in female participants. In a crude model, high HbA1c levels were significantly associated $(P=0.031)$ with two of the negative appraisal items, which involved the inability of managing their diabetes even with taking insulin (ITAS $1, \quad \beta \pm \mathrm{SE} \quad[95 \% \quad \mathrm{CI}], \quad 0.313 \pm 0.144$ [0.028-0.598], $P=0.046$ ) and their difficulty in manipulating the insulin device (ITAS 15 , "it is difficult to inject the right amount of insulin correctly at the right time every day," $\beta \pm \mathrm{SE}$ [95\% CI], $0.251 \pm 0.149$ [- 0.044 to 0.545$]$ ).

After fully adjusting for other risk factors, female participants expressed a mixed response concerning their appraisal of the insulin treatment protocols. The female participants were significantly associated $(P<0.05)$ with ITAS 15 (difficulty with insulin injection) and their elevated detection of $\mathrm{HbA} 1 \mathrm{c}(\beta \pm \mathrm{SE}[95 \% \mathrm{CI}]$, $0.341 \pm 0.155[0.034-0.647])$. In addition, the female participants had concerns about the potential deterioration of their existing health condition (ITAS 12, "taking insulin means my health will deteriorate"), which was significantly associated $(P<0.05)$ with their higher HbA1c levels ( $\beta \pm$ SE [95\% CI], $0.455 \pm 0.190$ [0.078-0.832]). Even with these negative perceptions, female participants did believe that insulin treatment could benefit their health status (ITAS 8, "taking insulin helps to improve my health") as there was a significant association $(P=0.021)$ between this item and lower 
Table 3 Multiple linear regression models comparing the psychologic status in females with HbAlc

\begin{tabular}{|c|c|c|c|c|c|c|c|}
\hline \multicolumn{4}{|c|}{ Crude model } & \multicolumn{4}{|c|}{ Fully adjusted model } \\
\hline $\begin{array}{l}\text { HbA1c } \\
(\%)\end{array}$ & $\beta \pm S E$ & $95 \% \mathrm{CI}$ & $P$ value & $\begin{array}{l}\text { HbA1c } \\
\text { (\%) }\end{array}$ & $\beta \pm S E$ & $95 \% \mathrm{CI}$ & $P$ value \\
\hline ITAS 1 & $0.313 \pm 0.144$ & $0.028-0.598$ & 0.046 & ITAS 8 & $-0.495 \pm 0.211$ & -0.913 to -0.077 & 0.021 \\
\hline \multirow[t]{2}{*}{ ITAS 15} & $0.251 \pm 0.149$ & $-0.044-0.545$ & 0.031 & ITAS 12 & $0.455 \pm 0.190$ & $0.078-0.832$ & 0.019 \\
\hline & & & & ITAS 15 & $0.341 \pm 0.155$ & $0.034-0.647$ & 0.030 \\
\hline
\end{tabular}

The analysis was calculated with adjustment for the following factors: (1) age, (2) marital/economic/educational status, (3) familial history of diabetes, (4) duration of diabetes, (5) type of insulin injection, (6) daily insulin dose/bodyweight, (7) comorbidities, and (8) caregiving status

CI confidential interval, ITAS (+) positive appraisal for the Insulin Treatment Appraisal Scale, ITAS 1 taking insulin means I have failed to manage my diabetes with diet and tablets, ITAS 8 taking insulin helps to improve my health, ITAS 12 taking insulin means my health will deteriorate, ITAS 15 it is difficult to inject the right amount of insulin correctly at the right time every day, $S E$ standard errors

Values were significant at $P<0.05$

measured levels of HbA1c $(\beta \pm \mathrm{SE}[95 \% \mathrm{CI}],-$ $0.495 \pm 0.211[-0.913$ to -0.077$])$.

\section{Association Between the Cost of Insulin and Diabetic Supplies with Hba1c}

With respect to the financial cost of using insulin, 106 patients (39.1\%) acknowledged that the purchase of sufficient quantities of diabetic supplies, such as lancets, blood glucose test strips, alcohol swabs, or insulin pen needles, was expensive. However, this was not a mitigating factor in the measured levels of HbA1c, since there was no significant difference $(P=0.925)$ in HbA1c levels between patients who reported that the diabetic supplies were expensive $(8.4 \pm 1.6 \%)$ and those that did not $(8.4 \pm 1.6 \%)$. In addition, only 4 (1.5\%; $P=0.344)$ of the total patients, admitted that they would administer a smaller dose of insulin than prescribed because of the cost of an insulin syringe was very low in our study.

In both male and female patients, the previously described significant association between the ITAS scores and HbA1c was not affected by adjusting the analyses to include either the costs of insulin or its associated diabetic supplies (data not shown).

\section{DISCUSSION}

This study investigated whether psychologic and/or financial issues may be associated with plasma HbA1c levels in a population of Korean T2D patients already being treated with insulin. Notably, we found that male patients had negative perceptions of insulin treatment whereas female respondents were mixed with both negative and positive appraisals of their use of insulin. In both male and female patients, a negative appraisal of insulin treatment was associated with elevated levels of $\mathrm{HbAc1}$, which we considered as our index of poor glycemic control. On the other hand, a positive appraisal of insulin treatment by female participants was significantly associated with lower HbA1c levels. There was no statistical association with financial hardship in the control of patient glycemia, even though many patients of both sexes acknowledged that the cost of insulin and other supplies was a negative issue.

Unlike the current study, most of the previous studies investigating PIR were primarily focused on the delay in the initiation of insulin therapy $[9-11,18]$. About one-third of the uncontrolled T2D patients were reluctant to start insulin upon recommendation by their physician [19]. There is an apparent diabetes- 
related distress phenomenon, which refers to the patient's psychologic burden because of living with and managing their diabetes, which affects some diabetic patients' willingness to accept insulin therapy. It is known that diabetes-related distress can increase morbidity, mortality, and socio-medical costs [20-22]. Moreover, a recent population-based study conducted in patients with T2D reported that females were associated with higher diabetesrelated distress compared to males and those distressors were associated with higher HbA1c levels and suboptimized self-management [23]. This is somewhat consistent with our study where females had significantly higher HbA1c levels compared to males. However, the overall score in the ITAS questionnaire did not differ between male and female participants. Moreover, unlike the males, female participants showed a mixed response of positive and negative appraisals that were significantly associated with the levels of HbA1c whereas males were only associated with negative appraisals. It is not clear why male and female patients expressed different psychometric patterns concerning insulin treatment, but we postulate that this could be related to regional or social variations where the other studies were primarily non-Asian populations [19]. In addition, Asian females may demonstrate greater compliance with recommendations made by their physicians than their male counterparts [24-26]. Regardless, further education is still needed to develop a more positive attitude toward insulin treatment by T2D patients.

In addition to the psychologic barriers, there may be economic barriers that limit the utilization of insulin in the treatment of hyperglycemia [14, 15]. The acute and chronic diabetic complications associated with poor glycemic control are a major socioeconomic burden, so there is a continuing need to maintain and, if needed, develop social safety nets for provision of insulin and its paraphernalia $[14,15]$. Regardless of the financial burden, insulin remains the gold standard to treat hyperglycemia and is an essential life-saving treatment, so its continued use cannot be solely dictated by the price. In South Korea, the insurance coverage policy for assisted devices related to insulin treatment was established initially in 2015 for patients with type 1 diabetes. In August 2018, the support policy expanded to include T2D patients $>19$ years old using insulin [27]. Therefore, the reason that the current pool of study participants may not be negatively impacted by the cost of using insulin could be the activation of this new policy. The medical community, including individual clinicians, should ensure that continued financial aid is provided to reduce any burden on this patient population for whom insulin treatment will be an inevitable course of treatment.

As with all studies, there are some limitations that should be acknowledged. First, this was a single-center study and was conducted at a tertiary referral hospital in Cheongju City of Chungcheongbuk-do Province, South Korea. Currently, South Korea offers national health insurance service to nearly every Korean national, but patients are not completely subsized for some of their medical care. In some cases, they be required to cover their treatment expenses at a certain rate (usually $30 \%$ of their entire medical cost). Therefore, the results of our study may be limited to the local geographical area and not be directly comparable to other countries with more diverse economic and racial populations. Second, the cross-sectional study design does not permit us to definitively establish a causal relationship between PIR with diabetes-related distress and glycemic control. Even with these recognized limitations, this study does provide new meaningful associations between HbA1c levels and psychologic factors adjusted for various confounding factors in T2D patients.

\section{CONCLUSIONS}

In conclusion, female T2D patients with a positive perception toward insulin treatment were associated with lower HbA1c levels, which was considered to be our index of improved glycemic control. Both males and females tended to have specific negative perceptions about insulin use, which was associated with increased HbA1c levels. Therefore, further 
education for T2D patients is essential to help promote a more positive environment around the use of insulin. Either the physician or outside social networks need to ensure that patients realize that insulin needs to be included in their treatment regimen to best control their glycemic levels and ultimately improve their longterm health condition.

\section{ACKNOWLEDGEMENTS}

We thank the participants of this study.

Funding. This study and the Rapid Service Fee were supported by a 2019 research grant from the Chungcheong Society of the Korean Society of Endocrinology (Dr. Eu Jeong Ku) (grant no. 2019). The funding source did not have any input in the study design, data collection, interpretation of the results, preparation of the manuscript, or publishing decision.

Authorship. All named authors meet the International Committee of Medical Journal Editors (ICMJE) criteria for authorship for this article, take responsibility for the integrity of the work as a whole, and have given their approval for this version to be published.

Authorship Contributions. TO and EJK conceived and designed the experiments. EJK acquired and analyzed the data and was responsible for the initial draft of the manuscript. EJK and PF revised the final manuscript. TO, HJJ, EJK, and DHL contributed materials. TO was responsible for the final completed version of the manuscript, which was approved by all of the authors.

Disclosures. Eu Jeong $\mathrm{Ku}$, Dong-Hwa Lee, Hyun Jeong Jeon, Frank Park, and Tae Keun Oh have nothing to disclose.

Compliance with Ethics Guidelines. The study was performed according to the principles of the revised Declaration of Helsinki, a statement of ethical principles to provide guidance to physicians and other participants in medical research involving human subjects and approved by the ethics committee of Chungbuk National University Hospital (IRB no. 2019-05019). Informed consent was obtained from all participants prior to inclusion in the study.

Data availability. The data included sensitive patient information. If additional information is needed regarding the data collection process and results, contact the corresponding author directly.

Open Access. This article is licensed under a Creative Commons Attribution-NonCommercial 4.0 International License, which permits any non-commercial use, sharing, adaptation, distribution and reproduction in any medium or format, as long as you give appropriate credit to the original author(s) and the source, provide a link to the Creative Commons licence, and indicate if changes were made. The images or other third party material in this article are included in the article's Creative Commons licence, unless indicated otherwise in a credit line to the material. If material is not included in the article's Creative Commons licence and your intended use is not permitted by statutory regulation or exceeds the permitted use, you will need to obtain permission directly from the copyright holder. To view a copy of this licence, visit http:// creativecommons.org/licenses/by-nc/4.0/.

\section{REFERENCES}

1. Schwartz SS, Epstein S, Corkey BE, Grant SF, Gavin JR 3rd, Aguilar RB. The time is right for a new classification system for diabetes: rationale and implications of the beta-cell-centric classification schema. Diabetes Care. 2016;39(2):179-86.

2. U.K. Prospective Diabetes Study 16. Overview of 6 years' therapy of type II diabetes: a progressive disease. U.K. Prospective Diabetes Study Group. Diabetes. $1995 ; 44(11): 1249-58$.

3. Inzucchi SE, Bergenstal RM, Buse JB, Diamant M, Ferrannini E, Nauck $M$, et al. Management of hyperglycemia in type 2 diabetes, 2015: a patientcentered approach: update to a position statement of the American Diabetes Association and the 
European Association for the Study of Diabetes. Diabetes Care. 2015;38(1):140-9.

4. Wright A, Burden AC, Paisey RB, Cull CA, Holman RR, Group UKPDS. Sulfonylurea inadequacy: efficacy of addition of insulin over 6 years in patients with type 2 diabetes in the U.K. Prospective Diabetes Study (UKPDS 57). Diabetes Care. 2002;25(2): 330-6.

5. Turner R, Cull C, Holman R. United Kingdom Prospective Diabetes Study 17: a 9-year update of a randomized, controlled trial on the effect of improved metabolic control on complications in non-insulin-dependent diabetes mellitus. Ann Intern Med. 1996;124(1 Pt 2):136-45.

6. Ku EJ, Lee DH, Jeon HJ, Oh TK. Effectiveness and safety of empagliflozin-based quadruple therapy compared with insulin glargine-based therapy in patients with inadequately controlled type 2 diabetes: An observational study in clinical practice. Diabetes Obes Metab. 2019;21(1):173-7.

7. Khunti K, Nikolajsen A, Thorsted BL, Andersen M, Davies MJ, Paul SK. Clinical inertia with regard to intensifying therapy in people with type 2 diabetes treated with basal insulin. Diabetes Obes Metab. 2016;18(4):401-9.

8. Fulcher G, Roberts A, Sinha A, Proietto J. What happens when patients require intensification from basal insulin? A retrospective audit of clinical practice for the treatment of type 2 diabetes from four Australian centres. Diabetes Res Clin Pract. 2015;108(3):405-13.

9. Peyrot M, Rubin RR, Kruger DF, Travis LB. Correlates of insulin injection omission. Diabetes Care. 2010;33(2):240-5.

10. Brod M, Kongso JH, Lessard S, Christensen TL. Psychological insulin resistance: patient beliefs and implications for diabetes management. Qual Life Res. 2009;18(1):23-32.

11. Polonsky WH, Fisher L, Guzman S, Villa-Caballero L, Edelman SV. Psychological insulin resistance in patients with type 2 diabetes: the scope of the problem. Diabetes Care. 2005;28(10):2543-5.

12. Larkin ME, Capasso VA, Chen CL, Mahoney EK, Hazard B, Cagliero E, et al. Measuring psychological insulin resistance: barriers to insulin use. Diabetes Educ. 2008;34(3):511-7.

13. Hunt LM, Valenzuela MA, Pugh JA. NIDDM patients' fears and hopes about insulin therapy. The basis of patient reluctance. Diabetes Care. 1997;20(3):292-8.
14. Bhatia K, Chang EY, Bilal M. Insulin cost and underuse in patients with diabetes. JAMA Intern Med. 2019;179(6):849.

15. Herkert D, Vijayakumar P, Luo J, Schwartz JI, Rabin TL, DeFilippo E, et al. Cost-related insulin underuse among patients with diabetes. JAMA Intern Med. 2019;179(1):112-4.

16. Nam S, Chesla C, Stotts NA, Kroon L, Janson SL. Factors associated with psychological insulin resistance in individuals with type 2 diabetes. Diabetes Care. 2010;33(8):1747-9.

17. Snoek FJ, Skovlund SE, Pouwer F. Development and validation of the insulin treatment appraisal scale (ITAS) in patients with type 2 diabetes. Health Qual Life Outcomes. 2007;5:69.

18. Ng CJ, Lai PS, Lee YK, Azmi SA, Teo CH. Barriers and facilitators to starting insulin in patients with type 2 diabetes: a systematic review. Int J Clin Pract. 2015;69(10):1050-70.

19. Hosomura N, Malmasi S, Timerman D, Lei VJ, Zhang H, Chang L, et al. Decline of insulin therapy and delays in insulin initiation in people with uncontrolled diabetes mellitus. Diabet Med. 2017;34(11):1599-602.

20. Egede LE, Walker RJ, Bishu K, Dismuke CE. Trends in costs of depression in adults with diabetes in the united states: medical expenditure panel survey, 2004-2011. J Gen Intern Med. 2016;31(6):615-22.

21. Fisher L, Mullan JT, Arean P, Glasgow RE, Hessler D, Masharani U. Diabetes distress but not clinical depression or depressive symptoms is associated with glycemic control in both cross-sectional and longitudinal analyses. Diabetes Care. 2010;33(1): 23-8.

22. Hermanns N, Kulzer B, Krichbaum M, Kubiak T, Haak T. How to screen for depression and emotional problems in patients with diabetes: comparison of screening characteristics of depression questionnaires, measurement of diabetes-specific emotional problems and standard clinical assessment. Diabetologia. 2006;49(3):469-77.

23. Nanayakkara N, Pease A, Ranasinha S, Wischer N, Andrikopoulos S, Speight J, et al. Depression and diabetes distress in adults with type 2 diabetes: results from the Australian National Diabetes Audit (ANDA) 2016. Sci Rep. 2018;8(1):7846.

24. Babwah F, Baksh S, Blake L, Cupid-Thuesday J, Hosein I, Sookhai A, et al. The role of gender in compliance and attendance at an outpatient clinic for type 2 diabetes mellitus in Trinidad. Rev Panam Salud Publica. 2006;19(2):79-84. 
25. Yeh JZ, Wei CJ, Weng SF, Tsai CY, Shih JH, Shih CL, et al. Disease-specific health literacy, disease knowledge, and adherence behavior among patients with type 2 diabetes in Taiwan. BMC Public Health. 2018;18(1):1062.

26. Vlassoff C. Gender differences in determinants and consequences of health and illness. J Health Popul Nutr. 2007;25(1):47-61.
27. Korean National Health Insurance Service (2018) Insulin pump syringe, needle health insurance support expansion policy. In: service Knhi, editor. 2018. https://www.nhis.or.kr/bbs7/boards/B0039/ 26793; Accessed 31 Aug 2020 